\title{
Experimental study of liquid to air membrane energy exchanger (LAMEE) performance by measuring its temperature fields
}

\author{
Junze Chu, Ziwei Chen, Hongyu Bai, Jie Zhu*
}

Department of Architecture and Built Environment, the University of Nottingham

University Park, Nottingham, NG7 2RD, UK

*Corresponding author, E-mail address: jie.zhu@nottingham.ac.uk

\begin{abstract}
Many studies have already been conducted to assess liquid to air membrane energy exchanger (LAMEE) performance by numerical and experimental methods. However, the LAMEE temperature field is still an unknown area due to the operation difficult. In this study, an experimental method is adopted to investigate the performance of LAMEE by measuring its temperature fields. The effects of main parameters such as the solution temperature, solution concentration and air relative humidity, are investigated. The results show that the air relative humidity and solution temperature have negative influences on the LAMEE efficiency. It is found that the total effectiveness reduces $2.7 \%$ and $7.7 \%$ when the air relative humidity increases from $62 \%$ to $74 \%$, and the solution temperature changes from $18^{\circ} \mathrm{C}$ to $26^{\circ} \mathrm{C}$, respectively. Increasing the solution concentration decreases the sensible effectiveness while enhancing the latent and total effectiveness. The total effectiveness increases $3.5 \%$ as the solution concentration increase from $30 \%$ by $39 \%$. These results are useful to optimize the LAMEE in the future.
\end{abstract}

Key words: Experimental method; parameter effects; LAMEE performance, temperature field.

\section{Introduction}

Energy crisis becomes a serious problem in recent years and buildings consume about forty percent of the total energy [1]. Heating, cooling and ventilation take large proportion in the building energy consumption, and people spend most of their time on indoor activities [2]. Liquid desiccant air conditioning (LDAC) system saves large amount of energy compared with the traditional mechanical type in dealing with latent heat; low regeneration temperature means that LDAC system can be powered by low grade thermal energy such as waste heat or 
renewable energy, which shows the potential of its application in the rural areas and developing countries [3]. Carryover problem of LDAC can be avoided by applying semi-permeable membranes in dehumidifier and regenerator [4]. The semi-permeable membranes separate the air stream and desiccant solution to prevent the carryover of liquid desiccant droplets. In a liquid to air membrane energy exchanger (LAMEE), only water vapour and heat can pass through the membrane, while the solution is not allowed to go through the membrane. Although the membrane increases the moisture and heat transfer resistances in the LDAC, it provides a safety environment for human beings. There are a lot of numerical study for the LAMEE temperature field [5-10], however the experimental test of the temperature field is still not carried out. In this paper an experimental method is adopted to investigate the performance of a LAMEE by measuring its temperature fields. The experimental results of the LAMEE temperature fields can be applied for validating the numerical modelling; moreover, it could be used as the reference data for optimization of the LAMEE, for example, adjusting the solution distribution according to the temperature field (more solution at high temperature area).

\begin{tabular}{|ll|}
\hline Nomenclature & Concentration $\left(\mathrm{kg} / \mathrm{m}^{3}\right)$ \\
$c_{p}$ & Specific heat capacity $(\mathrm{J} / \mathrm{kgK})$ \\
$\mathrm{Cr} *$ & Heat capacity ratio \\
$\mathrm{d}$ & Width of the channel $(\mathrm{m})$ \\
$\mathrm{D}$ & Diffusivity $\left(\mathrm{m}^{2} / \mathrm{s}\right)$ \\
$\mathrm{H}$ & Height of the LAMEE $(\mathrm{m})$ \\
$\mathrm{H}^{*}$ & Operating factor \\
$\mathrm{k}$ & Thermal conductivity $(\mathrm{W} / \mathrm{mK})$ \\
$k_{m}$ & Membrane water vapour permeability $(\mathrm{kg} / \mathrm{m} \mathrm{s})$ \\
$\mathrm{L}$ & Length of the LAMEE (m) \\
LAMEE & Liquid to air membrane energy exchanger \\
\hline
\end{tabular}




\begin{tabular}{|ll}
\hline LDAC & Liquid desiccant air conditioning \\
RH & Relative humidity $(\%)$ \\
T & Temperature $\left({ }^{\circ} \mathrm{C}\right)$ \\
W & Width of the LAMEE $(\mathrm{m})$ \\
$\mathrm{W}_{\text {air } / \text { sol }}$ & Humidity ratio $(\mathrm{kg} / \mathrm{kg})$ \\
Greek symbols & \\
$\varepsilon$ & Effectiveness \\
$\delta$ & Membrane thickness $(\mathrm{m})$ \\
$\rho$ & Density $\left(\mathrm{kg} / \mathrm{m}^{3}\right)$ \\
Subscripts & \\
air & Sonsible \\
in & Solution flow \\
lat & Inlet \\
sen & Latent \\
\hline
\end{tabular}

\section{Methodology}

47 In order to get the temperature field inside the membrane based flat plate dehumidifier, a number of temperature sensors are installed in one air channel and one adjacent solution channel, the dehumidifier structure and geometry information are shown in Fig.1. Each channel is installed with 15 sensors as indicated in Fig.2. In the air channel, every 5 sensors are stuck

51 in one strip in horizontal direction, while in the solution channel, every 3 sensors are fixed in 52 one strip in vertical direction. 
54

61 62 properties.

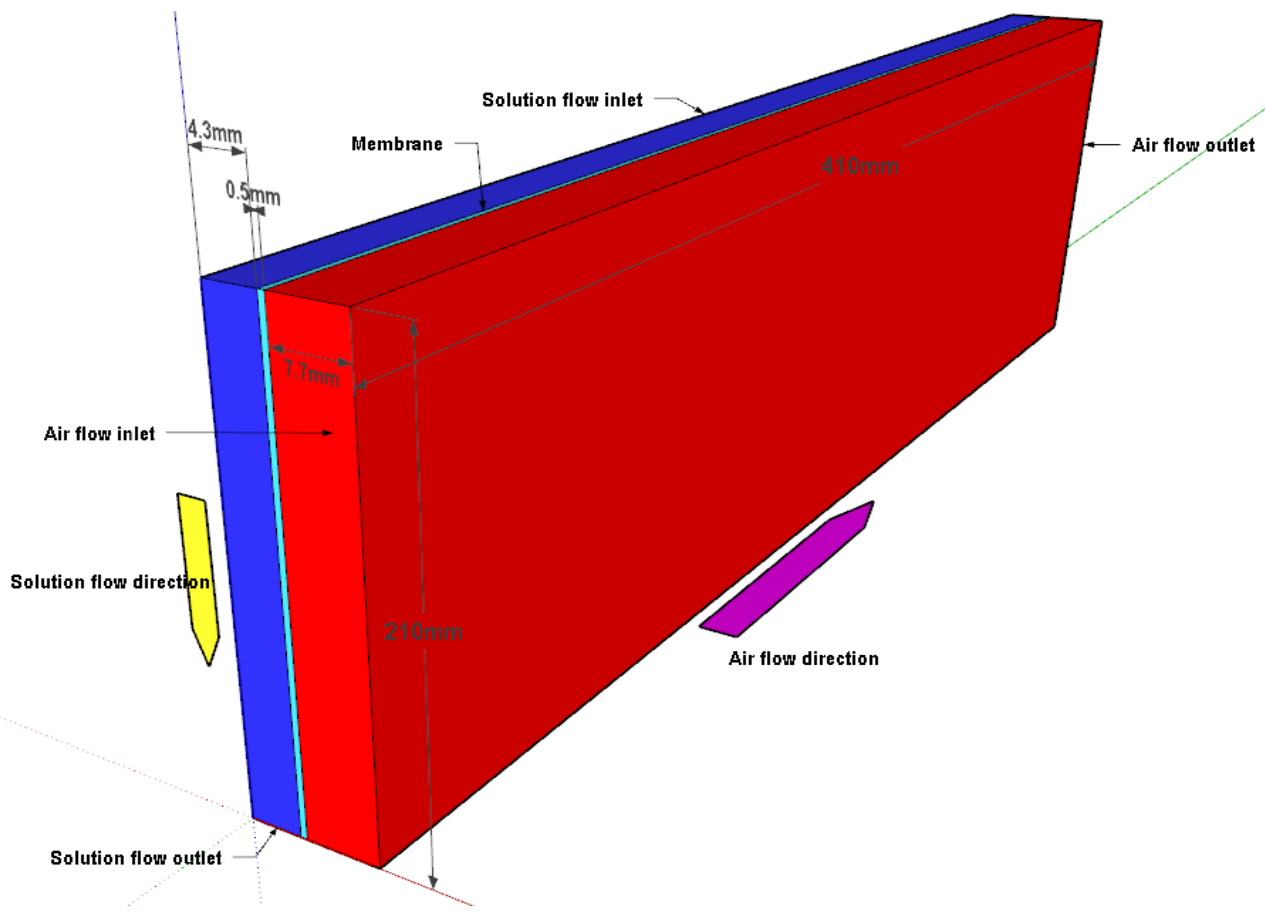

Fig.1: Structure and geometry information for the air and solution channels.

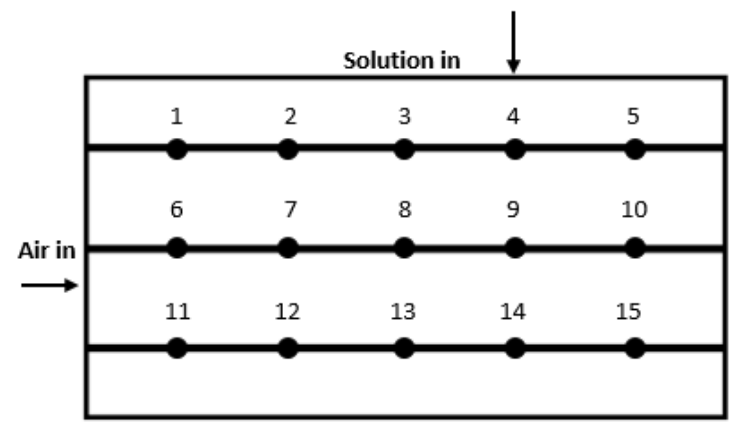

(a)

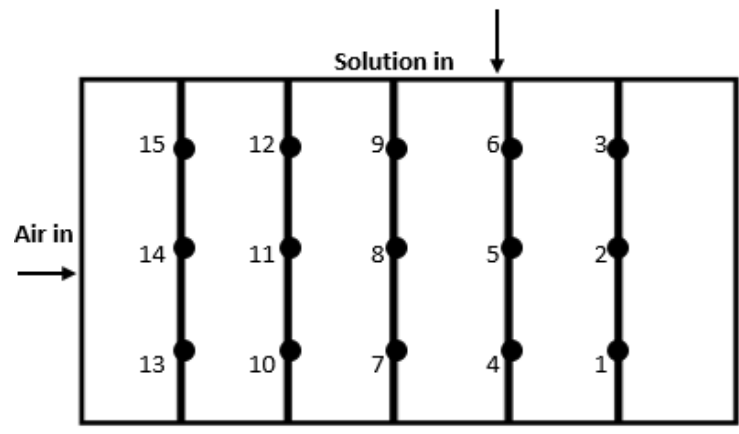

(b)

Fig.2: Sensor arrangements in (a) air channel; (b) solution channel.

The specifications of the dehumidifier and membrane, and the desiccant solution and air properties are listed in Table1.

61 Table 1: Dehumidifier specifications, membrane physical properties, air and desiccant solution

\begin{tabular}{|c|c|c|c|c|c|}
\hline Symbol & Unit & Value & Symbol & Unit & Value \\
\hline $\mathrm{L}$ & $\mathrm{m}$ & 0.41 & $k_{\text {air }}$ & $\mathrm{W} / \mathrm{mK}$ & 0.03 \\
\hline $\mathrm{W}$ & $\mathrm{m}$ & 0.23 & $k_{\text {sol }}$ & $\mathrm{W} / \mathrm{mK}$ & 0.53 \\
\hline $\mathrm{H}$ & $\mathrm{m}$ & 0.21 & $D_{\text {air }}$ & $m^{2} / \mathrm{s}$ & $2.46 \times 10^{-5}$ \\
\hline
\end{tabular}




\begin{tabular}{|c|c|c|c|c|c|}
\hline$d_{a i r}$ & $\mathrm{~m}$ & 0.0077 & $D_{\text {sol }}$ & $m^{2} / \mathrm{s}$ & $0.892 \times 10^{-2}$ \\
\hline$d_{\text {sol }}$ & $\mathrm{m}$ & 0.0043 & $c_{p, a i r}$ & $\mathrm{~J} / \mathrm{kgK}$ & 1020 \\
\hline$\delta_{m e m}$ & $\mathrm{~m}$ & $0.5 \times 10^{-3}$ & $c_{p, s o l}$ & $\mathrm{~J} / \mathrm{kgK}$ & 3200 \\
\hline $\boldsymbol{k}_{m e m}$ & $\mathrm{~W} / \mathrm{mK}$ & 0.3 & $\rho_{\text {air }}$ & $\mathrm{kg} / \mathrm{m}^{3}$ & 1.29 \\
\hline $\boldsymbol{k}_{\boldsymbol{m}, \boldsymbol{m e m}}$ & $\mathrm{Kg} / \mathrm{ms}$ & $3.87 \times 10^{-6}$ & $\rho_{\text {sol }}$ & $\mathrm{kg} / \mathrm{m}^{3}$ & 1247 \\
\hline
\end{tabular}

63

64

65

66

67

68

69

70

71

72

76

\section{Performance index}

Effectiveness is the commonly used performance index in energy exchanger. Sensible, latent and total effectiveness are applied to investigate the energy exchanger performance respectively. The sensible effectiveness is the ratio between the actual and maximum possible sensible heat transfer rates in the energy exchanger and given by:

$$
\varepsilon_{\text {sen }}=\frac{T_{\text {air }, \text { in }}-T_{\text {air }, \text { out }}}{T_{\text {air, }, \text { in }}-T_{\text {sol, in }}}
$$

Where $\varepsilon_{\text {sen }}$ is the sensible effectiveness, $T_{\text {air, in }}$ is the inlet air temperature $\left({ }^{\circ} \mathrm{C}\right), T_{\text {air }, \text { out }}$ is the outlet air temperature $\left({ }^{\circ} \mathrm{C}\right), T_{\text {sol,in }}$ is the inlet solution temperature $\left({ }^{\circ} \mathrm{C}\right)$.

The latent effectiveness is the ratio between actual and maximum possible latent heat transfer rates in the energy exchanger and defined as:

$$
\varepsilon_{\text {lat }}=\frac{W_{\text {air,in }}-W_{\text {air }, \text { out }}}{W_{\text {air, in }}-W_{\text {sol, in }}}
$$

Where $\varepsilon_{\text {lat }}$ is the latent effectiveness, $w_{\text {air,in }}$ is the inlet air humidity ratio $(\mathrm{kg} / \mathrm{kg}), w_{\text {air,out }}$ is the outlet air humidity ratio $(\mathrm{kg} / \mathrm{kg}), w_{\text {sol,in }}$ is the inlet solution equilibrium specific humidity ratio $(\mathrm{kg} / \mathrm{kg})$.

The total effectiveness is the ratio between the actual and maximum possible energy transfer rates in the energy exchanger and given by:

$$
\varepsilon_{\text {tot }}=\frac{\varepsilon_{\text {sen }}+H^{*} \varepsilon_{\text {lat }}}{1+H^{*}}
$$

Where $\varepsilon_{\text {tot }}$ is the total effectiveness, $H^{*}$ is the operating factor.

Equations (1) to (3) are only meaningful when the solution capacity rate is higher than or equal to the air capacity rate $\left(C r^{*} \geq 1\right)$.

\section{Experiment setting}




\begin{tabular}{|c|c|c|c|c|c|c|c|c|c|}
\hline Num & $\begin{array}{c}\text { Air RH } \\
(\%)\end{array}$ & Num & $\begin{array}{c}\mathrm{T} \text { sol }\left({ }^{\circ} \mathrm{C}\right) \\
\mathrm{C}_{\text {sol }}=30 \%\end{array}$ & Num & $\begin{array}{c}\text { T sol }\left({ }^{\circ} \mathrm{C}\right) \\
\mathrm{C}_{\text {sol }}=33 \%\end{array}$ & Num & $\begin{array}{c}\mathrm{T} \text { sol }\left({ }^{\circ} \mathrm{C}\right) \\
\mathrm{C}_{\mathrm{sol}}=36 \%\end{array}$ & Num & $\begin{array}{c}\text { T sol }\left({ }^{\circ} \mathrm{C}\right) \\
\mathrm{C}_{\text {sol }}=39 \%\end{array}$ \\
\hline 1 & 62 & 5 & 18 & 10 & 18 & 15 & 18 & 20 & 18 \\
\hline 2 & 66 & 6 & 20 & 11 & 20 & 16 & 20 & 21 & 20 \\
\hline 3 & 70 & 7 & 22 & 12 & 22 & 17 & 22 & 22 & 22 \\
\hline 4 & 74 & 8 & 24 & 13 & 24 & 18 & 24 & 23 & 24 \\
\hline & & 9 & 26 & 14 & 26 & 19 & 26 & 24 & 26 \\
\hline
\end{tabular}

93

94

96

97

98

99

100

101

102

103

Table 3: Temperature field results for basic parameter setting.

\begin{tabular}{|c|c|c|c|c|c|c|c|c|c|}
\hline \multicolumn{5}{|c|}{ Air side $\left({ }^{\circ} \mathrm{C}\right)$} & \multicolumn{5}{|c|}{ Solution side $\left({ }^{\circ} \mathrm{C}\right)$} \\
\hline 1 & 2 & 3 & 4 & 5 & 15 & 12 & 9 & 6 & 3 \\
\hline 30.146 & 30.053 & 29.696 & 27.939 & 26.531 & 19.515 & 19.822 & 19.52 & 19.975 & 19.157 \\
\hline 6 & 7 & 8 & 9 & 10 & 14 & 11 & 8 & 5 & 2 \\
\hline 30.428 & 30.069 & 29.901 & 28.061 & 27.161 & 21.229 & 19.954 & 19.783 & 19.975 & 19.179 \\
\hline 11 & 12 & 13 & 14 & 15 & 13 & 10 & 7 & 4 & 1 \\
\hline 32.232 & 31.863 & 30.445 & 28.384 & 27.553 & 23.937 & 22.608 & 20.33 & 20.155 & 19.415 \\
\hline
\end{tabular}

$30 \%, 33 \%, 36 \%$ and $39 \%$ concentration solutions are tested under five different inlet solution temperatures.

\section{Results \& discussion}

The temperature field results for basic parameter setting are shown in Table 3. From Table 3, it can be seen that the air temperature decreases along its flow direction and increases in the vertical direction. As for the solution temperature, it increases along the solution flow direction, the highest temperature occurs at the left bottom corner. The temperature maps are plotted with linear interpolation method as shown in Fig.3. 


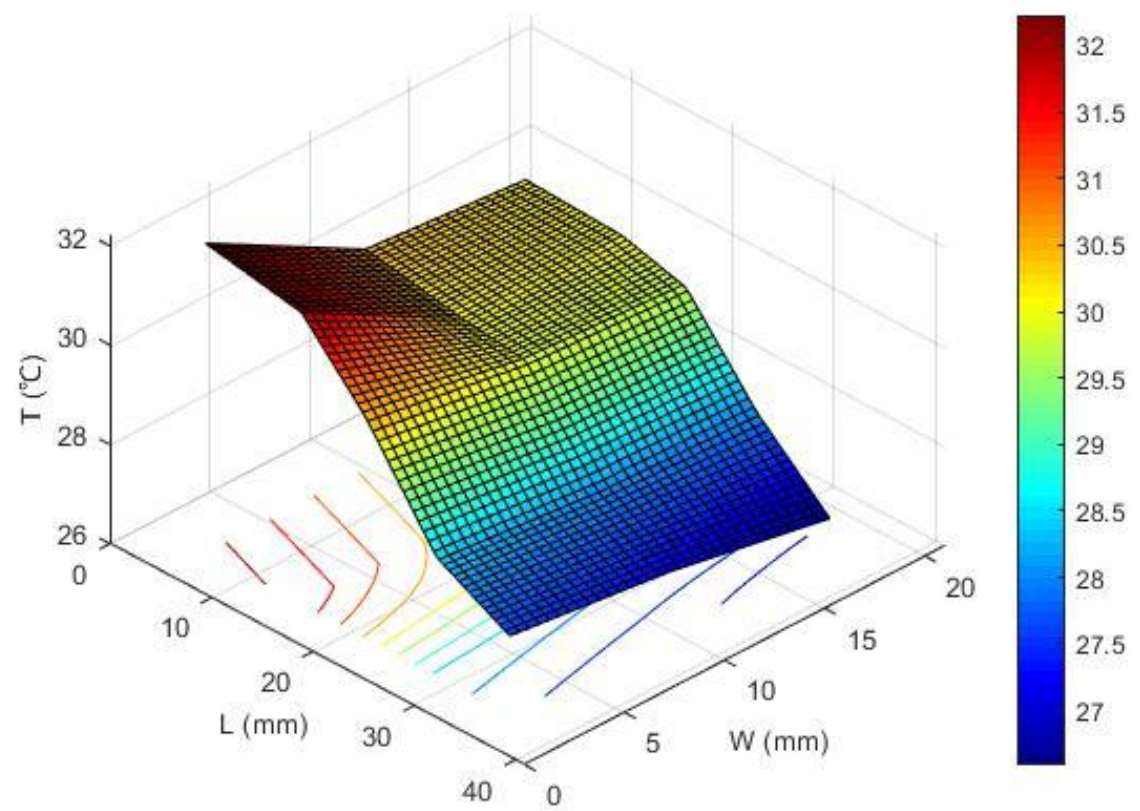

105

(a)

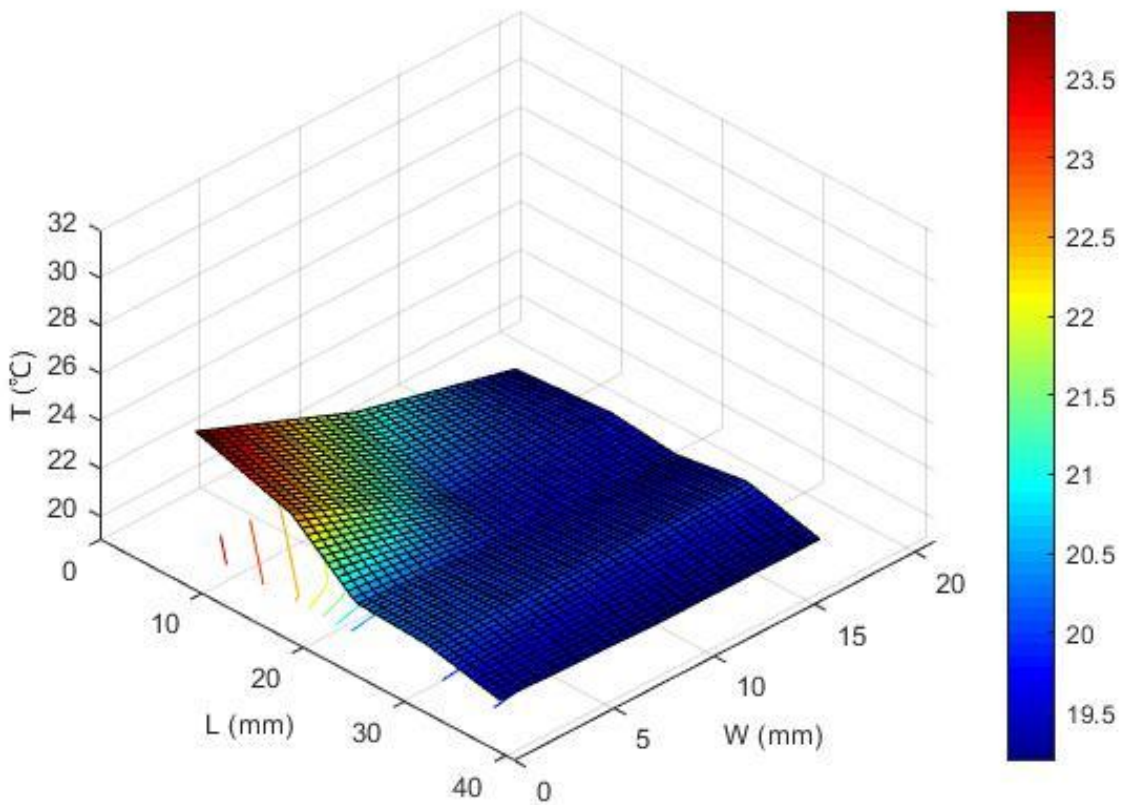

Fig.3: (a) Air temperature field; (b) Solution temperature field. 


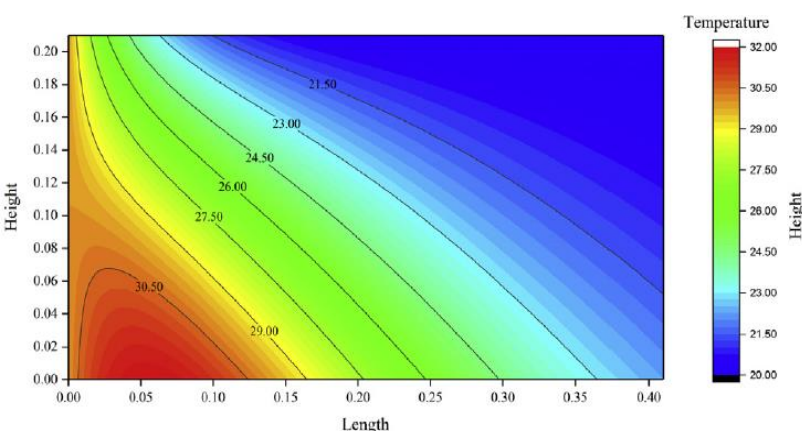

(a)

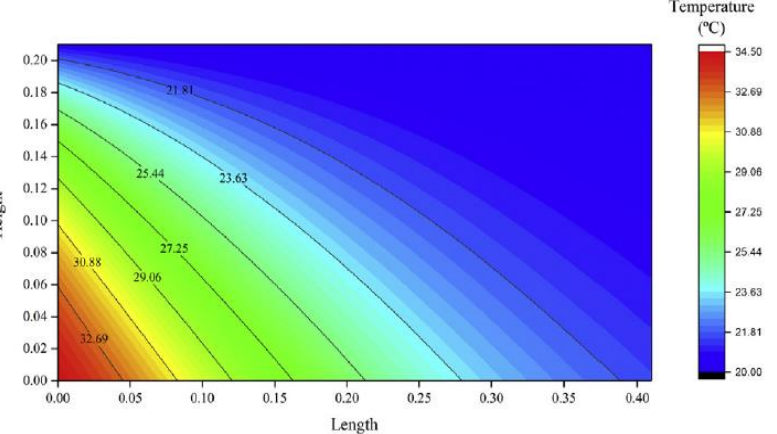

(b)

Fig.4: Temperature fields in previous work: (a) air side; (b) solution side [11].

113 From Fig.3 (a), it can be seen that the highest air temperature area is located at the cross section 114 of the air inlet and solution outlet. The air temperature in that area is even higher than the inlet air temperature because the plenty of latent heat is released. As indicated in Fig.3 (b), the highest solution temperature area is located at the bottom-left corner while the lowest

117 temperature field is at the top-right corner. Compared with the previous simulation results 118 shown in Fig.4, the experimental air and solution temperature variation tendencies correspond with the simulated ones. The similar variation tendency can be found in literature [9]. Therefore, the experimental results are convincible and can be used to investigate the LAMEE performance.

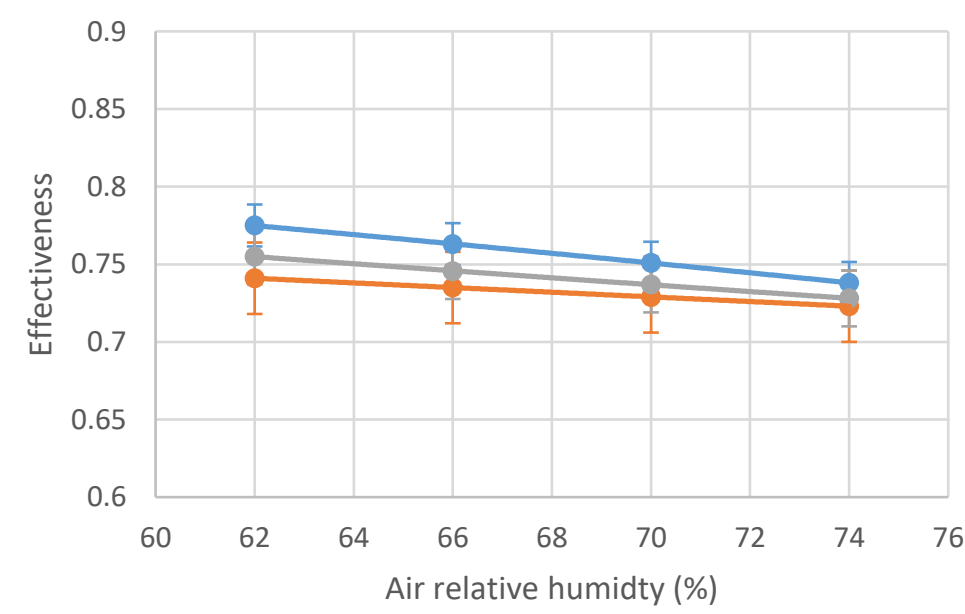

- Sensible effectiveness

- Latent effectiveness

- Total effectiveness

Fig. 5: Sensible, latent and total effectiveness variations with air RH. 
126 Fig.5 presents the air relative humidity influences on the sensible, latent and total effectiveness

127 of the LAMEE. Generally speaking, the air RH has little negative influence on the LAMEE 128 performance. For example, the sensible effectiveness decreases from 0.775 to 0.738 when the 129 air RH increases from $62 \%$ to $76 \%$. The main reason for this case is more latent heat released 130 in the solution side. In the tested range, the latent effectiveness decreases only about 0.018 but 131 the moisture remove rate increases $27.38 \%$. Therefore the performance index should be 132 properly adopted in practical application. The total effectiveness also decreases a little with the 133 air $\mathrm{RH}$ about 0.027 in the tested range.
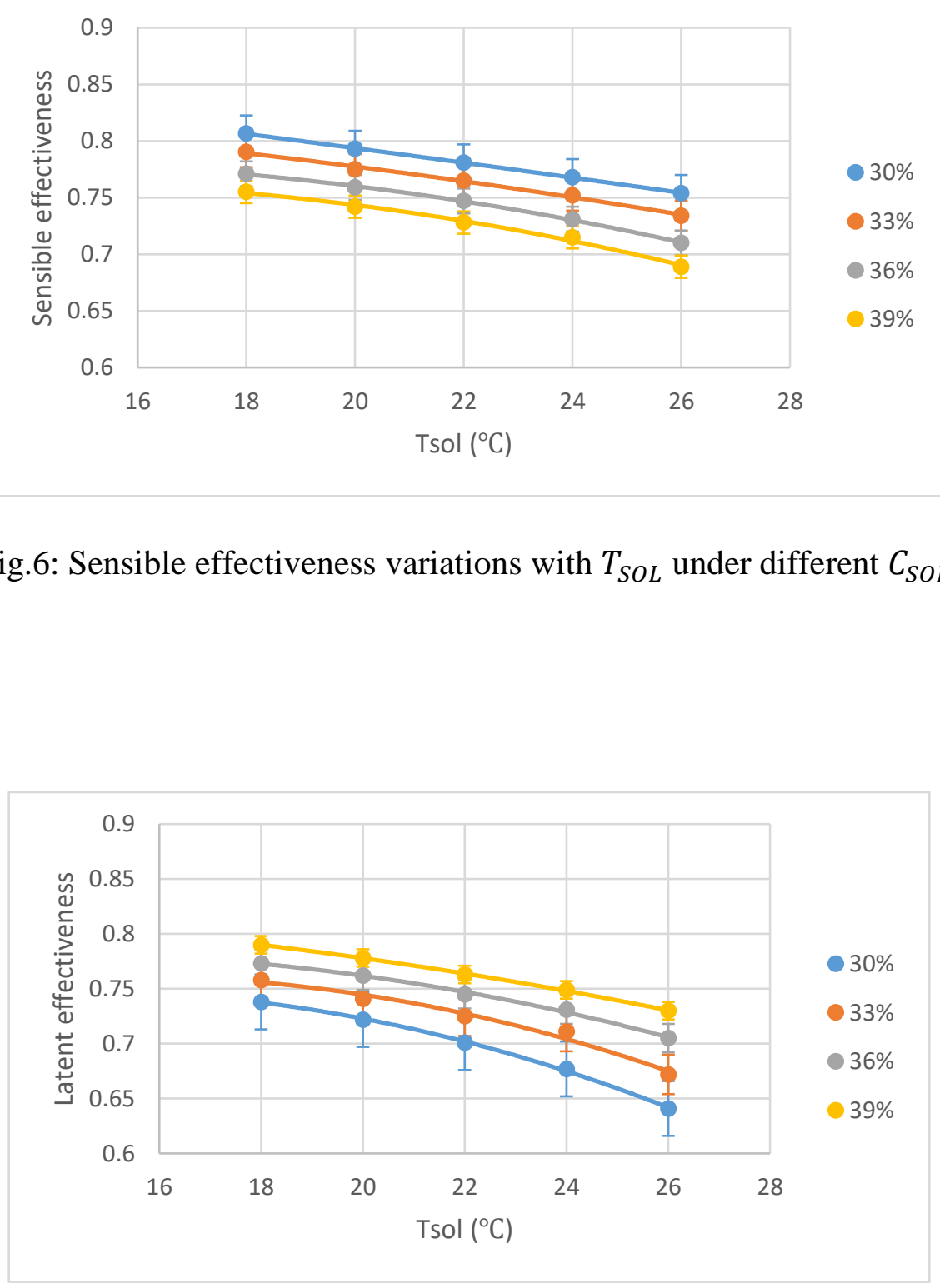


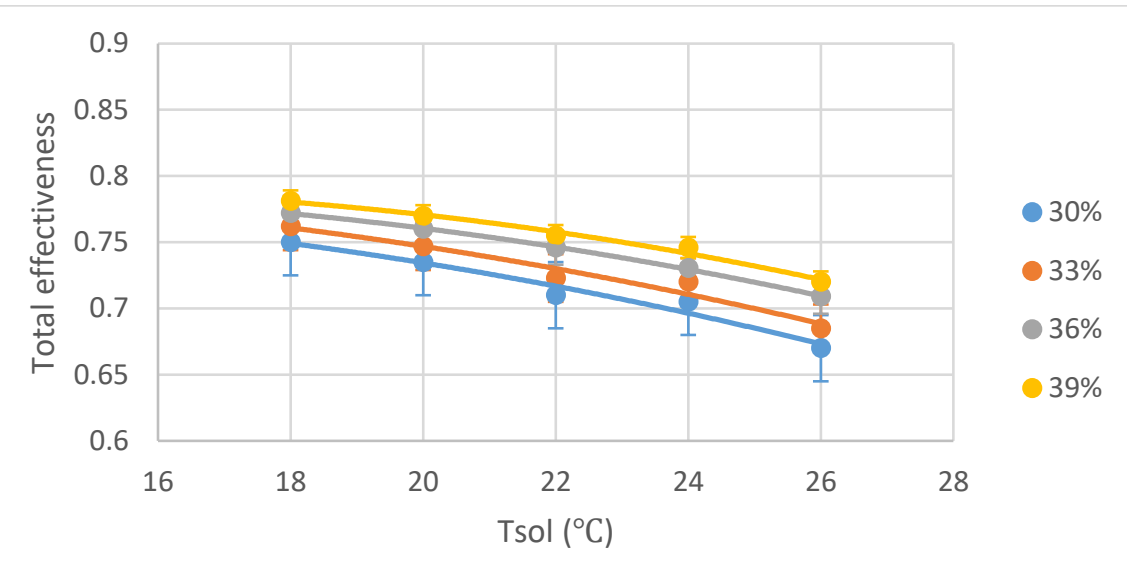

Fig.8: Total effectiveness variations with $T_{S O L}$ under different $C_{S O L}$.

Figs.6, 7 and 8 indicate the solution temperature and concentration influences on the effectiveness. It is obvious that the solution temperature has negative influence on the sensible, latent and total effectiveness. Increasing the solution temperature decreases the vapour pressure difference between the air and desiccant solution sides, then reduces the dehumidification performance. Enhancing the solution temperature reduces both the denomination and numerator in Eq. (1) at the same time but with larger numerator reduction. The influence of the liquid desiccant solution temperature on LAMEE performance is more obvious than the air RH's. For example, at $C_{S O L}=33 \%$, the total effectiveness reduces from 0.762 to 0.685 when the solution temperature changes from $18^{\circ} \mathrm{C}$ to $26^{\circ} \mathrm{C}$; while at $C_{S O L}=39 \%$, the corresponding total effectiveness decreases from 0.781 to 0.720 .

As for the solution concentration effect, increasing the solution concentration decreases the sensible effectiveness due to more moisture absorbed. In opposite, the high concentration solution makes contribution to the latent and total effectiveness. However, the influence on the total effectiveness is insignificant. For instance, the total effectiveness decreases from 0.770 to 0.735 when the solution concentration changes from $39 \%$ to $30 \%$ at the inlet solution temperature of $20^{\circ} \mathrm{C}$. Therefore for the practical application, this should be considered because only 5 percent or less effectiveness improvement is achieved in the experimental test. 
In this paper, the temperature field of a cross flow LAMEE is investigated experimentally. Some conclusions can be drawn as follows:

- The experimental temperature fields have the correct variation tendency and can be used to optimise the LAMEE performance.

- Air relative humidity has little effect on the LAMEE performance. In the tested range, the sensible, latent and total effectiveness only decrease $0.037,0.018$ and 0.027 respectively.

- Desiccant solution temperature has obviously negative influences on the sensible, latent and total effectiveness. At $C_{S O L}=33 \%$, the total effectiveness reduces from 0.762 to 0.685 when the solution temperature changes from $18{ }^{\circ} \mathrm{C}$ to $26{ }^{\circ} \mathrm{C}$; at $C_{S O L}=39 \%$, the corresponding total effectiveness decreases from 0.781 to 0.720 .

- The solution concentration has the negative effect on the sensible effectiveness while it has the positive influences on the latent and total effectiveness. However, only less than $5 \%$ effectiveness improvement is achieved in the experimental test. Therefore, its limited effect should be considered in practical application.

\section{Conflict of interest}

The authors declared that there is no conflict of interest.

\section{References}

[1] A.M Omer. Energy, environment and sustainable development. Renewable and Sustainable Energy Reviews 2008; 12:2265-300.

[2] X.D Cao, X.L Dai, J.J Liu. Building energy-consumption status worldwide and the stateof-the-art technologies for zero-energy buildings during the past decade. Energy and Buildings 2016; 128: 198-213.

[3] K.Daou, R.Z Wang, Z.Z. Xia. Desiccant cooling air conditioning: a review. Renewable and Sustainable Energy Reviews 2006; 10: 55-77.

[4] A.H Abdel-Salam, G.M Ge, G.J Simonson. Performance analysis of a membrane liquid desiccant air-conditioning system. Energy and Buildings 2013; 62:559-569.

[5] Y.M Luo, HX Yang, L Lu, RH Qi. A review of the mathematical models for predicting the heat and mass transfer process in the liquid desiccant dehumidifier. Renewable and Sustainable Energy Reviews 2014; 31:587-599. 
196

197

198

199

200

201

202

203

204

205

206

207

208

209

210

[6] Y.M Luo, HX Yang, Y Chen, YH Wang. Application of CFD Model in Analyzing the Performance of a Liquid Desiccant Dehumidifier. Energy Procedia 2016; 88:491-497.

[7] X.H Liu, Y Jiang, K.Y Qu. Heat and mass transfer model of cross flow liquid desiccant air dehumidifier/regenerator. Energy Conversion and Management 2007; 48:546-554.

[8] S.A Nada. Air cooling-dehumidification/desiccant regeneration processes by a falling liquid desiccant film on finned-tubes for different flow arrangements. International Journal of Thermal Sciences 2017; 113:10-19.

[9] R.S Das, S J. Performance characteristics of cross-flow membrane contactors for liquid desiccant systems. Applied Energy 2015; 141: 1-11.

[10] S.M Huang, M.L Yang, X.X Yang. Performance analysis of a quasi-counter flow parallelplate membrane contactor used for liquid desiccant air dehumidification. Applied Thermal Engineering 2014; 63:323-332.

[11] H.Y Bai, J Zhu, Z.W Chen, J.Z Chu. Parametric analysis of a cross-flow membrane-based parallel-plate liquid desiccant dehumidification system: Numerical and experimental data. Energy and Buildings 2018; 158:494-508. 